\title{
Behaviour Support Program for Ian
}

\author{
Abdulaziz Alsolmi \\ Saint Louis University, USA
}

Abstract: Applied Behaviour Analysis and behaviour modification are tremendously important in the field of disability. There are many students with disability suffer from behaviour challenges and they are in great need of help them change their behaviour in order to enable them to learn and successfully engage with others in their social, educational and sport activities. In this paper, Ian has great behaviour challenges especially when he can not socially communicate with others and hitting wrist. Ian was observed to notice challenges and then treatment was given to help him overcome these difficulties. The behaviour was observed again to determine the functional relationship between the intervention and the behaviour change and there was great impact on Ian's behaviour.

\section{INTRODUCTION}

Special education and related services provides students with disability with support in tow main areas. First, according the law, they will be provided with appropriate education in their educational environment. Second, they will be provided with related services which enable students with disability to learn and engage with their peers in their environment. This paper will discuss the behaviour of six-year autistic student who suffer from some difficulties of screaming and hitting wrist. Also, the student will expose to assessment and treatment to change undesirable behaviour.

\section{PRogram'S BEHAVIOURAL OBJECTIVES}

This intervention program will be applied to Ian6 years old boy that has challenging behaviour of screaming and hitting wrist. A functional behaviour assessment was conducted to analyse the problem behaviours in the natural environment. Ian was observed for three days in different settings and some information gathered through interviewing the parents on Ian's problem behaviours.

From the Functional behaviour assessment conducted, it was obviousthat Ian's challenging behaviours serve some functions. They are as follow:

- To get and tell what he wants, for example, using "no" when he would not like to work.

- To get involve with peers in the activities that he enjoys to strengthens the social skills.

- To use visual approaches as communication toll, for example raising the picture when he needs anything.

Ian's parents are concerned about current Ian's behaviour will affect his life in the future especially in his self-care as well as his social interaction with his mates who hanging around with.

A behavioural intervention plan is designed to help decreasing Ian's problem behaviour and to promote positive behaviour. The objectives of this intervention program as following:

- Ian's behavior of screaming and biting his wrist will reduce to one time of occurrence a week for 5 consecutive weeks. 
- Ian will build good social skills in order to have good relationship with his peers and minimize the conflict which might come up during the interaction.

\section{STRATEGIES}

This therapistadopted TEACCH as a strategic intervention technique through continuous involvement. However, rather than placing emphasis on clinical services this therapist placed emphasis on didactic techniques. In addition training and instruction were adopted in the classroom environment. Replacement Ian's behaviour, coping strategy and antecedent strategies will be implemented in this intervention program.

\section{REPLACEMENT BEHAVIOUR}

The problem behaviour that is performed by Ian has been recognized to serve some functions; one of them is to tell things that he wants instead of biting his wrist. For example when he would not like to do specific work, he would use simple and ease words such as 'no'. During the performance of the intervention plan, Ian should carry out a replacement behaviour which serves the same function that his problem behaviour serves.

In this case, Ian will be taught functional communication skills especially that he is taught how to ask something by using key words such as yes. Also, he should be taught how to use "no" when he does not to do or participate in specific thing.The same important way to replace Ian's problem behaviour is to provide him with some visual approaches such as cards and pictures. This method will enable him to communicate and give his parents an idea aboutsome specific things that he wants to get or do.

In another case, Ian can be taught basic social skills of sharing or borrowing things. He can be taught how to interact with his peers through participation or group game. This procedure will let ham engaging with his friends while they play as well as communicating some basic words. He will say "My turn" when he wants to play with his friend or "it is your turn" when he wants to exchange his things with other friends.

\section{COPING UP STRATEGY}

The coping up strategy of this therapist was focused on enabling Ian to learn basic skills. In other words it was focused on learning self help skills such as eating food and taking drinks. In the process this therapist identified how best Ian could cope up with simple tasks like holding the spoon and the fork and learning table manners.

This institutional-pedagogical intervention determinedapproach to environmental adjustment/readjustment contingency-specific programs would be considered as a more suitable alternative to many other approaches. Thus the delineation of associated outcomes would depend on a perspective focused analysis of the seminal literature on the subject of autism(Hannah, 2001).

\section{RATIONALE FOR THE BSP}

Replacement behavior is the behavior that we want to replace the unwanted/challenging behavior. In other word, when support the students to replace a good behavior instead of the unwanted one through applying some strategies. The replacement behavior serves the same function that is performed by problem behavior. The purpose ofreplacement behavior training is to identify a socially accepted behavior that have the same function as the problem behavior.

Available literature on the subject places less emphasis on exogenous variables perhaps due to the fact that it has been conclusively proved that autism is a genetic disorder. Despite this proof there is also a parallel attempt being made by teaching communities at large that behavioral tendencies of the autistic child could be altered with dynamic combinations of internal and external factors.Some researchers have extensively focused on the use and abuse of freedom to achieve predefined goals on resource allocation and utilization. 
TEACCH is one such approach that this therapist found out to be of greater significance. While the specialized classroom setting might be sparsely populated by autistic children, a positive correlation or a regression cannot be established with flimsier data gathered through a haphazard process of researching on the instincts of the researcher. This phenomenon has been illustrated by many writers on autism especially with reference to the specialized classroom structure and the autistic child's place therein. What such theoretical paradigms put forth as inherent classroom management practices would have a bearing on the outcomes of overall programs. The autistic child not only occupies the center point but also is the center of attention that invariably leads to far reaching outcomes for further research(Moyes, 2002).

Some writers stress the need to focus on antecedents of autistic behaviours rather than the consequences. Their argumentative line essentially presumes the existence of a positive correlation between autistic behaviour and the magnitude of non-intervention. The latter is occasioned by the generalized approach to autism in which mainstreaming and inclusion are ruled out as divergent contingency planning in controlling autism. There is also the need for an analysis of the causal factors that enhance teaching/learning outcomes in the special education classroom management context. There has been a degree of negligence in this sphere in autism relatedintervention programs. Failure to define appropriateness and timeliness of intervention under TEACCH approach could have been a major reason behind the mismatch between efforts at the specialized classroom setting level and external environmental intervention which often fails to acknowledge the existence of a dynamic relationship between the therapist and the autistic child.

\section{DATA BASED ON PREVIOUS INTERVENTION PROGRAMS}

The data collection for this intervention plan is the same with the data collection method that I did in the FBA.

Before intervention (During FBA)

\begin{tabular}{|l|l|l|l|l|l|l|l|}
\hline $\mathbf{5}$ & & & & & & & \\
\hline $\mathbf{4}$ & & & & & & & \\
\hline $\mathbf{3}$ & & & & & & & \\
\hline $\mathbf{2}$ & & & & & & & \\
\hline $\mathbf{1}$ & & & & & & & \\
\hline $\begin{array}{l}\text { Time/no. } \\
\text { of times } \\
\text { occurred }\end{array}$ & $8.30-9.00$ & $9.00-9.30$ & $10.00-10.30$ & $10.30-11.00$ & $11.00-11.30$ & $11.30-12.00$ & $12.00-$ \\
\hline
\end{tabular}

The graphic that is expected when the intervention plan is implemented.

\begin{tabular}{|c|c|c|c|c|c|c|c|c|}
\hline 5 & & & & & & & & \\
\hline 4 & & & & & & & & \\
\hline 3 & & & & & & & & \\
\hline 2 & & & & & & & & \\
\hline 1 & & & & & & & & \\
\hline $\begin{array}{l}\text { Time/no. } \\
\text { of times oc- } \\
\text { curred }\end{array}$ & $\begin{array}{l}8.30- \\
9.00\end{array}$ & $9.00-9.30$ & $\begin{array}{l}10.00- \\
10.30\end{array}$ & $\begin{array}{l}10.30- \\
11.00\end{array}$ & $\begin{array}{l}11.00- \\
11.30\end{array}$ & $\begin{array}{l}11.30- \\
12.00\end{array}$ & $\begin{array}{l}12.00- \\
12.30\end{array}$ & $8.30-9.00$ \\
\hline
\end{tabular}

Volume 2 
American Research Journal of Humanities and Social Sciences (ARJHSS)

\begin{tabular}{|l|l|}
\hline \hline Table 1.1 BSP Intervention \\
\hline No of weeks & 8 \\
\hline No of sessions & 40 \\
\hline No of hours for group activity per session & 2 \\
\hline No of hours for individual activity per session & 1 \\
\hline No of hours for teacher pupil interaction per session & 1 \\
\hline
\end{tabular}

\section{EFFECTIVENESS OF BSP}

Individual autistic child's response to an otherwise free environment alone ought to signify the raison d'être behind the very design andexecution of a teaching and/or learning process in that environment. While the significance of the absence of professional's prior learning might be factored into the weighing of learning outcomes of autistic children and the efficacy of the BSP, there is very little else by way of exogenous variables to consider in the TEACCH approach. By way of inference, intervention based on such an approach to managing a specialized classroom with autistic children would necessarily have an impact on the transformation and subsequent outcomesthough the extent to which a lack of intelligence, gathered before from the available literature on creating and sustaining effective intervention of practice by the professional therapist, would hinder his/her capacity to manage the BSP(Hesmondhalgh\&Breakey, 2001).The logical outcome is that professional efficiency in reflecting on action while involved in practice is influenced by prior learning to a certain extent though it's not conclusively desirable in creating and sustaining effective BSP related environments that are specialized settings or classrooms. However, it's pertinent to point out that Ian was more influenced in his speech and task skills learning process at the end of the program.

\section{GENERAL DESCRIPTION OF THE SCHOOL}

Ian attends a special primary school for students with disabilities from preschool to year 7. The school offers 4 programmes. Two programmes are designed for children who are 6 years of age and below in early intervention programmes. The other two programmes are designed for children from 6 to 12 years of age. One is a programme for those with physical and multiple disabilities and the other is a programme for those diagnosed with Autism Spectrum Disorder (ASD). The school uses the TEACCH approach in teaching children with ASD and the Assessment, Evaluation and Programming System (AEPS) curriculum is used to teach children in the other programmes (Fitzpatrick, 2004).

Ian's class is a 4-hour session class that comprises of 4 students inclusive of Ian. The children's age range is from 5 to 6 years and they are all diagnosed with autism. While two of the children are non-verbal, the other two are able to speak using 2 to 4 word phrases. Activities that are conducted in a group (entire class) are circle time, art, housecraft, hydrotherapy and snack. The individual needs of the students have been considered in the physical layout of the classroom. There are specific areas for specific activities and furniture is used to create clear boundaries for the students. Each student has his own work area and there is a common area where group activities are usually held. In addition, there is also a "rest" area and a "free play area".

\section{Preventive Strategies}

This teacher/therapist adopted a strategy based on behaviour change and modification. It was determined by the qualities embodied therein - developing a vision, inculcating the vision in the subject, leading the subject and defining goals and achievements. Thus the outcomes would have been influenced by the need to design and implement the follow-up preventive strategies.

Volume 2

Page 4 
One of the preventive strategies that might be suitable and useful to use with the whole class is the teaching of cleaning the classroom. When the students have known the strategy of the class cleaning, they will be more independent and can organize themselves without teachers put much effort to help them or to encourage them.

There are many classroom routines that can be taught such as leaving routine, lunch time, and changing task. With the teaching of changing task for example, it is likely that after finishing the lesson, the kids would return books in the right places and bring a new book. The signal for this routine could be a clap which contains the words exchange book. This routine can be presented by modelling to the students how to practice the routine.

- BSP was solely designed and implemented with special attention focused on the strategicpreventive initiatives and measures that were designed in conformance with the school curriculum though special classroom environments were designed to achieve a greater degree of convergence in the autistic child's behaviour.

\section{TEACHING SKILLS FOR SOCIAL INTERACTION}

Teaching social skills is one of intervention strategies which can be applied in the learning environment. It might be beneficial for the small group and the class as a whole. It is so important to teach students how to engage with others in order to strengthen their social skills. Teaching social skills has long been considered a critical factor for all students, especially for students who have additional needs (Conway, 2005). It obviously shows the importance of teaching social skills for students who have learning difficulties.

Autism is associated with the impairment of brain development leading to a lack of social intercourse and communication. Such children, usually before 3 years of age, also display repetitive behaviour. Since it involves a range of symptoms, a more convenient term to use is the autism spectrum disorders (ASD). For instance some milder signs might indicate a low level of impairment. Webster's New World Medical Dictionary defines autism as "a spectrum of neuropsychiatric disorders characterized by deficits in social interaction and communication, and unusual and repetitive behaviour. Some, but not all, people with autism are non-verbal" (www. webstersnewworlddictionary.com ).

As much as learning outcomes have been of greater relevance in the current BSP context, especially against the backdrop of an evolving paradigm for theoretical and conceptual framework development for the specialized setting classroom management by teachers and therapists, there is a particularly stronger need for a pedagogical convergence model to identify and construct a system of norms for the teacher to acquire autism related teaching skills. This is invariably so with regard to didactic reasoning in the specialized classroom management contexts. Autism is a behavioural disorder that requires a substantial amount of teaching skills to be utilized so that the classroom is not only better managed but also its subjects better taken care of (Nadesan, 2005).

This specialized classroom management task requires social intercourse to be of a particularly higher order. It's here that the pedagogical skills are shaped and reshaped. It's in fact a contingency demand for the teacher's social interaction skills which vary in dimension and depth. Strategic teaching skills require a degree of capacity enhancement from the viewpoint of the society. The teacher is both a catalyst and a rejuvenator. In other words social intercourse on the part of the teacher is not simply limited to meeting parents of autistic children but also extends to such diverse skills as those related to persuasion and transformation of attitudes.

\section{CONCLUSION}

To sum up, eligibility for special education and related services is significantly important to meet each child unique needs. Many students with disability suffer from behaviour disability which require immediate 
intervention and treatment to remediate such cases. Ian was help to appropriately use daily skills and was train on such daily living skills in order to be more independent. So, students with behavioural problems will be taught and trained on how they can modify their behaviour which lead to obvious independence.

\section{REFERENCES}

Autism Spectrum Disorder \& Behaviour Support, Retrieved from http://www.hnreach.on.ca/index.php/ counselling-a-supports-for-children-a-youth/developmental-services-for-children-a-youth/ autism-spectrum-disorder-a-behaviour-support, on October 30, 2010.

Conway, R. (2005). Encouraging positive interactions. In P. Foreman (Ed.), Inclusion in action. Australia: Thomson, Pty. Ltd.

New worlddictionary (2010). Definition of Autism Spectrum Disorder, retrieved from, www. webstersnewworlddictionary.com ), viewed on October, 312010.

Fitzpatrick, M. (2004). MMR and Autism: What Parents Need to Know, Oxford, Routledge.

Hannah, L. (2001).Teaching Young Children with Autistic Spectrum Disorders to Learn. London: Autism Asperger Publishing Company.

Hesmondhalgh, M. \&Breakey, C. (2001). Access and Inclusion for Children with Autistic Spectrum Disorders: Let Me In. London: Jessica Kingsley Publishers.

Moyes, R.A. (2002). Addressing the Challenging Behavior of Children with High-Functioning Autism/Asperger Syndrome in the Classroom: A Guide for Teachers

and Parents. London: Jessica Kingsley Publishers. Nadesan, M. (2005). Constructing Autism. Oxford: Routledge.

Sicile-Kara, C and Grandin, T 2003. Autism Spectrum Disorders: The Complete Guide, Ohio: Vermilion Publishers.

TEACCH Autism Program, Retrieved from http://www.teacch.com/, on October 30, 2010.

Citation: Abdulaziz Alsolmi, Behaviour Support Program for Ian, American Research Journal of Humanities and Social Sciences, Volume 2, 2016; pp:1-6

Copyright (C) 2016 Abdulaziz Alsolmi, This is an open access article distributed under the Creative Commons Attribution License, which permits unrestricted use, distribution, and reproduction in any medium, provided the original work is properly cited. 